\title{
24
}

\section{The impact of manufacturing strategy on the design of production manage- ment systems: An exploratory study}

\author{
J. Olhager and B. Cimander \\ Department of Production Economics, \\ Linköping Institute of Technology \\ S-58183 Linköping, Sweden \\ Tel: +46-13-281000 Fax: +46-13-288975 \\ E-mail: jan.olhager@ipe.liu.se
}

\begin{abstract}
This paper deals with the link between manufacturing strategy and the design of production management systems, from both theoretical and practical perspectives. We present a framework for relating the manufacturing strategy to the design of production management systems, based on theoretical approaches in the literature. The factors that influence the decisions to be made when designing such systems are identified. Furthermore, we apply the framework to four manufacturing firms. The results of this exploratory empirical study indicate the applicability and usefulness of the concepts in the theoretical framework.
\end{abstract}

\section{Keywords}

Production management, Manufacturing strategy, production management systems design, exploratory study

\section{INTRODUCTION}

The strategic development in many industries today is predominantly based on corporate marketing and finance decisions at the front with manufacturing being forced to react to these at the back end of the process. Manufacturing is merely treated as a support service, not as a full partner in developing the strategy it has to implement. Often, the result is that manufacturing is unable to successfully support 
the corporate strategy. However, it should be recognized that manufacturing can be used as a competitive weapon, if a strong link is established between strategy, manufacturing processes and the market place.

Manufacturing enterprises operate in a very dynamic environment. The requirements of the market place are constantly changing. Firms have to deal with shifts from make-to-stock to make-to-order, from low cost, more standardized products to an increasingly fragmented and differentiated market, technologies which allow flexibility at high volumes, customers willing to wait less and less time for delivery, etc. The globalization of economic activities and product markets intensifies many of these forces. Clearly, these pressures and responses require changes in both the production management systems and the underlying manufacturing processes. Typical responses are the adaptation of the just-in-time (JIT) philosophy, implementation of manufacturing resource planning (MRPII) systems, and the development of OPT-type principles for dealing with limiting resources (Optimized production technology). All these trends illustrate that management has realized the importance of combining both methodology and technology to overcome and take advantage of the increased complexity in order to expand business.

The purpose and task of production management systems is to support the manufacturing function of a company in order to achieve its corporate strategy. The system has to match the requirements of the specific mix of manufacturing environments the firm faces. Naturally, the needs of the manufacturing function will vary according to the type of manufacturing process and the products produced. These needs have to be transformed into the production management system, thereby setting its requirements and functionality.

Important factors that influence the decision to be made when designing a production management system are discussed in this paper. It is assumed that the system design will vary depending upon the distinctive needs of the market place, in which the company competes. As these needs are captured in the manufacturing strategy, a linkage between manufacturing strategy and design of the production management system can be established.

We also present an exploratory empirical study of four Swedish manufacturing firms. These companies are all performing well in their respective businesses and they represent different manufacturing environments. For each company the manufacturing strategy, markets, products and processes are described. Then, the decision variables for the design of production management systems are identified and the link between manufacturing strategy and system design is evaluated. The results provide insights into the applicability of the concepts used in the theoretical framework and their potential usefulness.

The results of this paper, in terms of framework and empirical study, should be of great interest to any manufacturing firm discussing or considering a change in market direction, manufacturing strategy and/or production management system design. 


\section{LINKAGE IN THEORY}

This section discusses the impact of manufacturing strategy on the design of production management system (PM systems or PMS). Two approaches found in literature are described and compared. The following should be kept in mind (Vollmann, et al., 1992): "There's an important distinction to draw in the process of matching manufacturing planning and control system design to firm requirements. The strategy is not the system. The system supports the execution of the strategy. ... The distinction is important because although the system is quite general, its use is very individual. Only after clearly understanding the strategy, the associated set of tasks the system is to perform, and the elements of the system itself, can the appropriate match be made".

Berry and Hill (1992) are among the few whom have discussed the link between system and strategy with reference to PM systems. This paper also appears in Hill (1994) and Vollmann, et al., (1992) in slightly different versions. Berry and Hill identify three relevant parts of a PM system, i.e. master scheduling, material planning and shop floor control. Each of these is linked to market and manufacturing characteristics. At the master level, three approaches are distinguished: make-to-stock, assemble-to-order and make-to-order. Material planning can either be rate-based or time-phased, and shop floor control can be either of MRP/push type or of JIT/pull type. Thus, this framework allows for 12 types of planning systems $(3 \times 2 \times 2)$. In practice, the links between the three levels may exclude some possibilities.

Bhattacharya and Coleman (1994) aim at identifying the decision variables that influence the design of the production control. They introduce a tetrahedron to describe the manufacturing environment in terms of market, product and process complexity. Market complexity as it pertains to manufacturing deals with competitive criteria in terms of order winners and order qualifiers, demand uncertainty, demand stability and volume per period. Product complexity is related to bill of material levels, options offered and degree of standardization. Routings, process technologies used and level of automation define the process complexity.

Both approaches identify three main parts of a PM system. Vollmann, et al., (1992) call them front-end, engine, and back-end. Bhattacharya and Coleman (1994) refer to them as "phases", emphasizing that the design of a production management system is an iterative process rather than a standardized set of yes-orno decisions. In the following, the latter approach is described in some detail as a basis for the case discussions. This is more detailed with respect to factors considered at various planning levels and is therefore used in the investigation of the linkage in practice.

The issues that are related to the planning levels above are summarized in Table 1, outlining the decision variables for system design. It also describes the link to the manufacturing environment and strategy in terms of market, product and process complexity. 
Table 1 Linkage between manufacturing strategy and production management system design. (based on Bhattacharya and Coleman, 1994)

\begin{tabular}{|c|c|c|c|}
\hline Manufacturing environment & & levels & \\
\hline Market complexity & low & $\leftrightarrow$ & high \\
\hline Product complexity & low & $\leftrightarrow$ & high \\
\hline Process complexity & low & $\leftrightarrow$ & high \\
\hline PMS decision variables & & levels & \\
\hline \multicolumn{4}{|l|}{ Phase 1: Long-term planning } \\
\hline Usage of PMS & $\begin{array}{l}\text { one for all } \\
\text { products }\end{array}$ & $\leftrightarrow$ & $\begin{array}{r}\text { one per product } \\
\text { group }\end{array}$ \\
\hline Order penetration point & MTS & ATO & MTO \\
\hline Forecast accuracy & high & $\leftrightarrow$ & low \\
\hline Production plan policy & level & $\leftrightarrow$ & chase \\
\hline \multicolumn{4}{|l|}{ Phase 2: Medium-term planning } \\
\hline Material plan & rate-based & $\leftrightarrow$ & time-phased \\
\hline Material planning & low detail & $\leftrightarrow$ & detailed \\
\hline Capacity planning & low detail & $\leftrightarrow$ & detailed \\
\hline Stability & high & $\leftrightarrow$ & low \\
\hline \multicolumn{4}{|l|}{ Phase 3: Short-term planning } \\
\hline Based on & JIT/pull & $\leftrightarrow$ & MRP/push \\
\hline Importance of capacity utilization & high & $\leftrightarrow$ & low \\
\hline Tracking/monitoring/expediting & low & $\leftrightarrow$ & high \\
\hline Linkage to phase $2 \& 1$ & low & $\leftrightarrow$ & high \\
\hline WIP inventory & low & $\leftrightarrow$ & high \\
\hline
\end{tabular}

Some of the level directions in Bhattacharya and Coleman (1994) have been rearranged to facilitate the identification of matches or mismatches between manufacturing strategy and design issues. For example, if market, product and process characteristics all have low complexity, the choice would typically be a make-to-stock (MTS), rate-based and JIT/pull system, focusing on the left hand side of the decision variable levels. If the manufacturing environment is highly complex, on the other hand, the system would most likely be make-to-order (MTO), time-phased and MRP/push, resulting in a profile at the right hand side of the spectrum. Assemble-to-order (ATO) situations mean that the order penetration point, i.e. the point where the product is linked to a specific customer order, splits the manufacturing process into two parts. The part before or upstream the order penetration point is basically make-to-stock manufacturing, whereas the latter part or downstream is make-to-order. This and other aspects on the positioning of the order penetration point are treated in Olhager (1994). 


\section{LINKAGE IN PRACTICE}

A questionnaire was developed with mainly open-end questions, concerned with market, product and manufacturing characteristics as well as PM system functionality and systems design process; details are found in Cimander (1995). Open-end questions were employed to determine how people were thinking and to stimulate critical evaluation and discussion. The managers interviewed in this sample have all been involved in the system design and implementation process. Even though none participated in strategy formulation, all are familiar with the companies' markets and the production processes, holding positions such as system manager, IT manager and production manager.

Four Swedish companies were chosen for this study. The criteria for selection was (i) the assumption that these companies were quite thorough when designing a PM system rather than selecting a standard system, and (ii) that all companies are performing well in their businesses. Also, these companies manufacture totally different products to totally different market. No similarities whether in size, volume, or characteristics can be noticed. Rather, they represent four different types of manufacturing environments. Product characteristics are shown in Table 2 , indicating that product complexity ranges from low to very high. "Product complexity" serves as an aggregate complexity indicator. The process structures also differ greatly in terms of complexity. Production process structure characteristics related to complexity are shown in Table 3, where "process complexity" serves as an aggregate indicator. The individual relative, scaled measures such as low-medium-high were evaluated by each respective company and compared and positioned by the authors.

Table 2 Summary of firms' product characteristics.

\begin{tabular}{ccccc}
\hline Firm & $A$ & $B$ & $C$ & $D$ \\
\hline Product lines & many & few & one & Few \\
\hline Final product variety & low & high & medium & Low \\
\hline $\begin{array}{c}\text { Individual product } \\
\text { volumes }\end{array}$ & high & medium & very low & high \\
\hline End-product maturity & $\begin{array}{c}\text { medium to } \\
\text { high }\end{array}$ & high & low & $\begin{array}{c}\text { medium to } \\
\text { high }\end{array}$ \\
\hline End product complexity & $\begin{array}{c}\text { low to } \\
\text { medium }\end{array}$ & $\begin{array}{c}\text { medium } \\
\text { to high }\end{array}$ & very high & medium \\
\hline BOM levels & few & many & very many & medium \\
\hline Product complexity & low & high & very high & low \\
\hline
\end{tabular}


Table 3 Summary of firms' process characteristics.

\begin{tabular}{ccccc}
\hline Firm & $A$ & $B$ & $C$ & $D$ \\
\hline Type of production & $\begin{array}{c}\text { process, } \\
\text { linked batch }\end{array}$ & $\begin{array}{c}\text { batch, flow } \\
\text { shops }\end{array}$ & $\begin{array}{c}\text { project, small } \\
\text { batches }\end{array}$ & $\begin{array}{c}\text { batch, flow } \\
\text { lines }\end{array}$ \\
\hline Level of mechanization & high & medium & medium & $\begin{array}{c}\text { medium to } \\
\text { high }\end{array}$ \\
\hline Product routings & rigid & $\begin{array}{c}\text { medium to } \\
\text { flexible }\end{array}$ & flexible & $\begin{array}{c}\text { medium to } \\
\text { rigid }\end{array}$ \\
\hline $\begin{array}{c}\text { Level of operations } \\
\text { interconnection }\end{array}$ & high & medium & low & $\begin{array}{c}\text { medium to } \\
\text { high }\end{array}$ \\
\hline Process complexity & low & medium & very high & medium \\
\hline
\end{tabular}

\subsection{Firm A: Pharmaceuticals}

Firm A is a multinational pharmaceutical company serving the global market. The main strategic goal is to maintain a steady growth, by continuously providing the market new and more effective products, relying on effective R\&D. The market demand stability is relatively high. Seasonal fluctuations occur, but are rather predictable. The market is considered of medium complexity. Many different product lines are produced in high volume and limited end product variety. Few BOM levels are needed; more or less simple mixture recipes are used. The product line complexity is considered low. Two quality dimensions dominate: the product must be an "effective medicine" and the product must be of $100 \%$ purity and conformance to the formula. The first is a matter for research and development, and the second a manufacturing issue. Also, delivery speed is identified as an order qualifier.

Firm A has a manufacturing strategy, however not well formulated. It aims at achieving superior quality, fostering delivery speed and increasing efficiency. The main manufacturing challenge is to keep pace with its yearly growth of more than $20 \%$, market share increases and the introduction of new product lines. The production process is highly automated with one production line for every product line, run as a linked batch process. The production system is complex in terms of know-how, automation, integration, and regulation, but simple in terms of routing options. The impact of marketing on manufacturing is that the output rate of the production lines has to increase and/or that new lines have to be set up.

Firm A produce finished goods on a make-to-stock basis. The products are distributed through warehouses and distributors to the customers. Forecasting accuracy should be a matter of importance, but in fact it is not. Due to the rapid growth of business, only the total annual output is determined. Medium-term planning is simplified due to the low process complexity. The end products leave the production line at a certain rate. Much latitude is left to the shop floor 
managers by providing support through the system but leaving the decisions to the front-line supervisors. Firm A expects to decentralize planning and control even further, emphasizing a belief in the capabilities of each individual. An MRP approach is used for shop floor scheduling and control. The degree of tracking and monitoring is high. As cost is of subordinate importance, capacity utilization becomes secondary. Batch sizes and WIP inventory are being reduced, subject to continuous improvement programs.

\subsection{Firm B: Fork lifters}

Firm B manufactures fork lifters for indoor use. The product range includes small, hand-pushed lifters as well as large forklift trucks. They are represented worldwide through a sales organization. They are steadily increasing their market share. The market is mature, limiting product innovations to ergonomic improvements. The order winners are superior delivery lead times in combination with customization flexibility. Demand uncertainty is very high, creating a rather high market complexity. Firm B offers four product lines. Fork lifters are complex products; an assembly of many components. Also, one product line has more than a thousand end-product variety possibilities. The product line complexity is considered high, even considering the modular and parametric design.

An explicitly stated manufacturing strategy does not exist, but the overall strategic plan specifies the goals for the functional areas. Only the manufacturing director participates in the formulation process. The competitive criteria are identified (i.e., delivery lead-time, quality, cost), but highly aggregated and not specified for the decision areas. Firm B produces in batch mode, striving for an increasing degree of flow orientation. Final assembly is manual, whereas parts manufacturing (fork, chassis, etc.) is highly mechanized, e.g. using FMS's in manufacturing cells.

Firm B uses an assemble-to-order approach. Due to the thousands of end-item options, forecasting accuracy is difficult to achieve. Consequently, a chase strategy is followed. The planning of the material flow through the plant is very detailed. Quantities and dates for each component and subassembly are specified, due to the relatively high product and process complexity. The capacity planning is also very detailed, and the material planning approach is time-phased. Still, planning is to a large extent decentralized, but the next system is expected to be very detailed and centralized. A pure MRP approach is pursued. The degree of tracking and monitoring is high. Batch sizes and WIP inventory are being reduced since 1989, when a lean production program was launched. 


\subsection{Firm C: Aircraft}

Firm $C$ is a high-tech company in the aircraft industry. The military division manufactures a modern multi-role combat fighter. The market is of very low complexity. Agreements on the number of planes and due-dates are long-term. However, the market for spare-parts is highly unpredictable. Technical support and after-sales support are important activities. Firm $\mathrm{C}$ only builds one type of airplane and the output rate is low. Prototypes are built, tests are performed and the latest technology is integrated into each new fighter. The product complexity is considered to be extremely high.

A manufacturing strategy is not defined. Firm $\mathrm{C}$ is about to start exporting and expects that the plane will be very competitive on the international market at least with respect to price. The project type production system is flexible in terms of production volume, product mix, machine, process and routing. Many different manufacturing technologies are used, creating a very complex process.

Firm C is a make-to-order company, but may at a later stage in the product life cycle shift towards assemble-to-order. The orders for the next decade are known. Thus, forecast "accuracy" is high. However, the bill of material is continuously subject to changes and modifications, and spare parts demand is uncertain. Material and capacity plans are very detailed, time-phased and centralized. The MRP/push approach is used for shop floor control. Tracking and monitoring of manufacturing orders is more important than capacity utilization. WIP inventory is related to the manufacturing lead-time in this one-of-a-kind project type of production and held at a medium level.

\subsection{Firm D: Microwave ovens}

Firm D manufactures microwave ovens for the world market. They focus on superior technical features, whereas most competitors pursue a low cost strategy. The market share worldwide is steadily increasing. The market requires product modifications every two to four years. Firm D is considered a prospector in the introduction of new features, justifying a higher price. Particular country-specific features, such as knobs, buttons and space design, have to be taken into account. Demand stability is high; seasonal fluctuations are negligible. The market complexity is considered low. Two major product lines account for $80-90 \%$ of the total output. The product variety is low, the basic difference being color. The endproduct complexity is medium, as is the number of BOM levels. Thus, the product line complexity is considered low.

Firm D does not explicitly state a manufacturing strategy. Microwave ovens are manufactured in batch and flow lines. Due to frequent model changes, production processes have to be flexible, explaining the high degree of manual operations. Still, the overall level of mechanization is considered to be medium to high. 
Firm D produces to stock. Forecasting is concerned with annual volumes. The approach to detailed material planning is a combination of time-phased and ratebased. Final assembly and some subassemblies are rate-based, whereas all other production areas are time-phased. Planning is centralized. Firm D uses a hybrid MRP/Kanban approach, considered a just-in-time system. $60 \%$ of the purchase orders are delivered just-in-time, and some directly to the point of usage. Fax machines are used on the shop floor for material ordering and call-offs. All these transactions are still planned and monitored by the MRP system. Aiming at becoming a world-class manufacturer, firm D performs "best practice" comparisons. Processes, operations, systems and structures are compared and evaluated worldwide, and then the "best" method found is implemented in all plants.

\section{SUMMARY AND COMPARISONS}

Not one of these four companies has a written statement about the manufacturing strategy. Still, all companies are performing well. They have employed production processes that correspond well to market characteristics. Formalized procedures could not be found, neither for analyzing the market dimension nor for choosing a production process. None of the companies has performed an assessment of the manufacturing function and determined the particular manufacturing tasks. Thus, system design decisions were taken by intuition and insight rather than by structure and systematic analysis of the market-manufacturing interface. All four companies seem to have process structures that correspond well with the product and market characteristics. The companies are continuously improving the processes and the correspondence to the market requirements.

The characteristics of the production management systems are summarized in Table 4. The corresponding firm letter marks the level for each company. If a letter is missing, the position could not be evaluated.

The table clearly indicates the range of manufacturing environments and the range of system designs. Firms $A$ and $D$ have similar system environments. Accordingly, the decision variable profiles for the production management systems show similarities, although firm $D$ is located more to the middle because of the mix of rate-based and time-phased planning. Firm $\mathrm{C}$ has a particular one-of-a-kind, project type of production, explaining the scattered profile. With an assemble-toorder approach, mixing MTS and MTO approaches, firm B takes an intermediate position. Low product and market complexity, level production plan, and high medium-term plan stability at firms $\mathrm{A}$ and $\mathrm{D}$ suggest that a further move towards a JIT/pull system and decentralized monitoring would be possible as indicated by their profiles in Table 4. 
Table 4 Firms' profiles regarding the link between manufacturing strategy and PMS design variables.

\begin{tabular}{|c|c|c|c|c|c|}
\hline Manufacturing environment & $\leftarrow$ & & levels & & $\rightarrow$ \\
\hline Market complexity (low - high) & & D & A & $B$ & \\
\hline Product complexity (low - high) & A D & & & & C \\
\hline Process complexity (low - high) & & & B D & & $\mathrm{C}$ \\
\hline PMS decision variables & $\leftarrow$ & & levels & & $\rightarrow$ \\
\hline \multicolumn{6}{|l|}{ Phase 1: Long-term planning } \\
\hline Usage of PMS (same - different) & $\mathrm{ABCD}$ & & & & \\
\hline Order penetration point (MTS - ATO - MTO) & A D & & B & & $\mathrm{C}$ \\
\hline Forecast accuracy (high - low) & $\mathrm{C}$ & & A D & & B \\
\hline Production plan policy (level - chase) & A D & & & & B \\
\hline \multicolumn{6}{|l|}{ Phase 2: Medium-term planning } \\
\hline Material plan (rate-based - time-phased) & A C B & & D & & \\
\hline Material planning (low detail - detailed) & & & D & & B C \\
\hline Capacity planning (low detail - detailed) & & & D & & B C \\
\hline Stability (high - low) & C A D & & B & & \\
\hline \multicolumn{6}{|l|}{ Phase 3: Short-term planning } \\
\hline Based on (pull - push) & & & D B & & A C \\
\hline Importance of capacity utilization (high - low) & A & & C B D & & \\
\hline Tracking/monitoring/expediting (low - high) & & & D B & & A C \\
\hline Linkage to phase $2 \& 1$ (low - high) & & & D B & & A C \\
\hline WIP inventory (low - high) & & B & A D C & & \\
\hline
\end{tabular}

The backgrounds to and motives for the design of production management systems are manifold. A new organization form in one firm resulted in a new production management system. The international sales organization in another firm suggested that an MRPII system be implemented in order to reduce the delivery lead times. Two years later, the same firm started a lean production program, which resulted in far-going modifications of the newly installed MRPII system.

All production management systems are primarily MRP-based, due to some complexity in the manufacturing environment. For firm B, MRP is utilized as a tool to rapidly transform individual customer orders into shop floor orders, which are then scheduled and released. For firms A and C, the MRP system also supports process documentation, which is essential for product quality and reliability reasons. Firm $D$ is moving towards a JIT system.

Using the Berry and Hill (1992) framework, focusing on MTS, ATO or MTO approaches to master planning, rate-based or time-phased detailed material planning and JIT/pull or MRP/push for shop floor control, would indicate a similar 
type of fit between strategy and system for the four companies. However, the framework used here provides a few more PMS decision variables.

All systems seem to perform well, designed for the particular manufacturing tasks and product/process constraints. Still, some inconsistencies could be identified between the system environment and the individual design decisions as well as between different elements of the system. Then, it is important to analyze the extent of and reasons for such inconsistencies. The system designers reported that they thought they knew the manufacturing process and the corresponding system characteristics that would best support the market, even though a systematic assessment of the manufacturing strategy was not undertaken.

\section{CONCLUSIONS}

The design decisions made by the four companies in this study seem to be captured well by the approach in Bhattacharya and Coleman (1994). This approach proved to be useful in practice, providing the managers of the participating firms with a comprehensive insight into the system structures and an understanding of some factors that influence the system design decisions. Some level directions (see Table 1 and 4), were rearranged to facilitate a systematic evaluation of the consistency of the system design. The market, product and process complexities indicate the functional requirements and the possible simplicity level of the PM system. Yet, special manufacturing environments may show a scattered profile. Then, a further analysis is needed to provide answers as to why the system is designed in such a way or if the system actually can and should be redesigned. Also, if the system includes a mix of push and pull short-term planning and/or a mix of rate-based and time-phased medium-term planning, it is not possible to clearly illustrate these combinations and links in the existing frameworks.

No company had a well formulated manufacturing strategy. Still, the match between on the one hand market, product and process characteristics and on the other the production management system was quite good. Thus, the ways in which the dimensions relevant to the manufacturing strategy are taken into consideration is of decisive importance, rather than the actual formulation of a manufacturing strategy. Still, formalized procedures and a clear statement of the manufacturing strategy would be beneficial in order to minimize the number of inconsistencies between the manufacturing task and the production management system design.

In summary, a model for linking manufacturing strategy to the design of production management system is needed and welcomed by manufacturing firms. However, there is a lack of research in this field. The results of this study suggest that the approaches discussed here need further refinement in order to truly support the design phase from a manufacturing strategy point of view. Such enhancements and the development of new models, approaches and frameworks are vital topics for further research. 


\section{ACKNOWLEDGEMENT}

The research is supported by grant from the Volvo Research Foundation and the Volvo Educational Foundation.

\section{REFERENCES}

Berry, W.L. \& Hill, T. (1992), Linking systems to strategy. International Journal of Operations and Production Management, 12(10), pp. 3-15.

Bhattacharya, A.K. \& Coleman, J.L. (1994), Linking manufacturing strategy to the design of a customized hybrid production control system. Computer Integrated Manufacturing Systems, 7(2), pp. 134-141.

Cimander, B. (1995), The impact of manufacturing strategy on the design of manufacturing planning and control systems. Research Report No. 131, Department of Production Economics, Linköping Institute of Technology.

Hill, T. (1994), Manufacturing strategy: text and cases (2 ${ }^{\text {nd }}$ Ed.), Irwin, IL.

Olhager, J. (1994), On the positioning of the customer order decoupling point, in 'Proceedings of the 1994 Pacific Conference on Manufacturing', Jakarta, pp. 1093-1100.

Vollmann, T.E., Berry, W.L. \& Whybark, D.C. (1992). Manufacturing Planning and Control Systems (3rd Ed.), Irwin, IL.

\section{BIOGRAPHY}

Jan Olhager is Associate Professor at the Department of Production Economics, Linköping Institute of Technology. He received a Master of Engineering from University of California at Berkeley and a Ph.D. from Linköping Institute of Technology. He has authored a book on manufacturing planning and control. He has published in international journals such as European Journal of Operational Research, International Journal of Operations and Production Management, International Journal of Production Economics, International Journal of Production Research and International Transactions in Operational Research. His research interests include manufacturing strategy, manufacturing planning and control, flexibility, and modelling and analysis of production management systems.

Berthold Cimander was a Visiting Researcher at the Department of Production Economics, Linköping Institute of Technology in 1995, on leave from Universität Hamburg. 